Check for updates

Cite this: RSC Adv., 2017, 7, 21556

\title{
Two-dimensional SnS nanoflakes: synthesis and application to acetone and alcohol sensors
}

\begin{abstract}
M. F. Afsar, ${ }^{\text {ab }}$ M. A. Rafiq (D) ${ }^{* b}$ and A. I. Y. Tok $^{c}$
SnS nanoflakes were synthesized using a solid state reaction method at $600{ }^{\circ} \mathrm{C}$ and their gas sensing properties were investigated. X-ray diffraction (XRD), energy dispersive X-ray spectroscopy (EDS) and Transmission Electron Microscopy (TEM) analysis revealed the formation of a pure, polycrystalline, orthorhombic phase of SnS nanoflakes. The response of the SnS nanoflakes sensor to reducing gases such as acetone and alcohols (ethanol, methanol and 1-butanol) was measured from $25^{\circ} \mathrm{C}$ to $200{ }^{\circ} \mathrm{C}$. The response of the SnS nanoflakes sensor was highest for acetone $\left(\sim 1000 \%\right.$ at $\left.100{ }^{\circ} \mathrm{C}\right)$. It was determined that the optimal operating temperature of the SnS nanoflakes sensor was $100{ }^{\circ} \mathrm{C}$ for acetone and 1-butanol. Fast response and recovery times of these sensors were observed for all gases. With an increase in temperature from $25^{\circ} \mathrm{C}$ to $200{ }^{\circ} \mathrm{C}$, response and recovery times of the SnS nanoflakes sensor were improved for all gases. Finally, the SnS nanoflakes sensor characteristics have been compared to the characteristics of other metal oxide/sulphide nanostructure sensors reported in previous studies. Moreover, the SnS nanoflakes sensor showed good stability and reproducibility at $100{ }^{\circ} \mathrm{C}$ for acetone. As acetone in human breath is a marker for diagnosis of diabetes, this work demonstrates a possible use of SnS nanoflakes in diabetes diagnosis.
\end{abstract}

Received 13th March 2017

Accepted 8th April 2017

DOI: $10.1039 / \mathrm{c} 7 \mathrm{ra03004e}$

rsc.li/rsc-advances properties of SnS nanoflakes. As the presence of acetone in human breath is an indication of diabetes, $\mathrm{SnS}$ nanoflakes could be used for diagnosis of diabetes. The reason to choose SnS nanoflake morphology for alcohol and acetone sensing is that it has been demonstrated previously that sensor based on 2D nanomaterials such as nanoflakes display excellent sensing of volatile compounds. ${ }^{10}$ In this study the SnS nanoflakes were synthesized by solid state reaction method. It is an easy and simple technique without the requirement of solvent or surfactant. This method is top-down approach to build the micro/nanostructures at higher temperatures because it facilitates the diffusion of ions or atoms through chemical reaction. ${ }^{17-19}$ Due to these reasons it was preferred over other techniques such as hydrothermal, solvothermal, polyol and laser ablation techniques for preparation of $\mathrm{SnS}$ nanostructures. ${ }^{20,21}$ In literature preparation of SnS nanoflakes by solid state reaction has not been reported.

\section{Experimental details}

Solid state reaction technique was used to prepare $\mathrm{SnS}$ nanoflakes using thiourea $\left[\mathrm{SC}\left(\mathrm{NH}_{2}\right)_{2}\right]$ and tin(Iv) acetate $\left[\mathrm{C}_{8} \mathrm{H}_{12} \mathrm{O}_{8} \mathrm{Sn}\right]$. These chemicals were of analytical grade. Stoichiometric amounts of thiourea and tin(Iv) acetate in the ratio of $1: 1$ were grinded in an agate mortar separately and then mixed in a crucible. The mixed powder was then heated in a tube furnace at $600{ }^{\circ} \mathrm{C}$ for $5 \mathrm{~h}$ in presence of argon flow. During heat treatment the heating and cooling rate was $3{ }^{\circ} \mathrm{C}$ per minute. Heat 


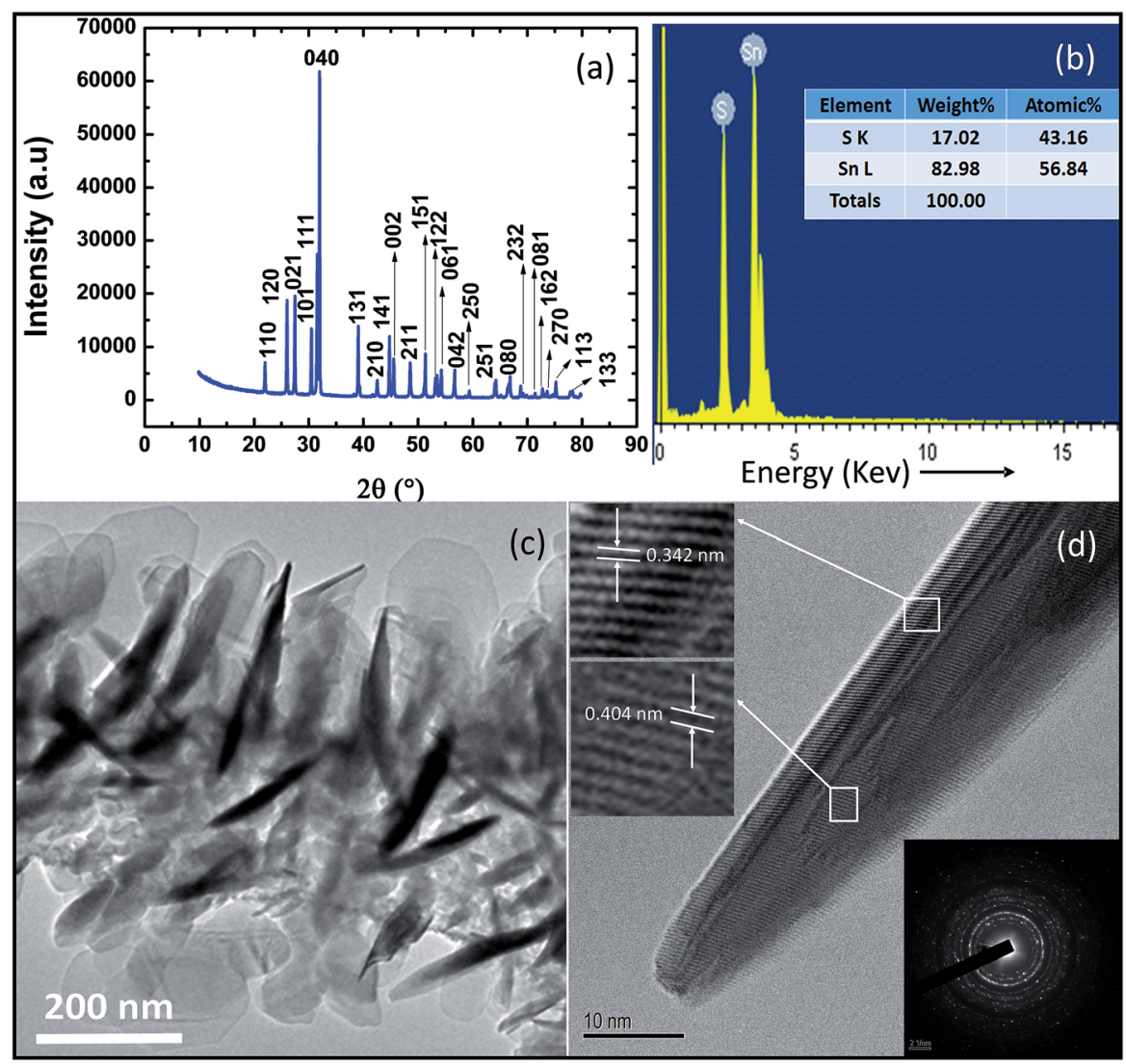

Fig. 1 Synthesized SnS nanoflakes (a) XRD spectrum (b) EDS analysis (c) TEM low resolution image (d) HRTEM image with SEAD diffraction image.

treatment yielded pure crystalline SnS powder with silver color because at above $500{ }^{\circ} \mathrm{C} \mathrm{SnS}$ is more likely to be formed..$^{22,23}$ The prepared $\mathrm{SnS}$ powder was then grinded for 10 minutes to obtain fine powder. Here we used thiourea as source of sulfur as it has slow decomposition rate as compared to highly reactive sulphides (such as sodium sulphide). This helps formation of nanostructures. ${ }^{17}$

The resulting powder was characterized using XRD "Bruker D8 Advance Powder" with $\mathrm{Cu} \mathrm{K} \alpha$ radiation $(\lambda=1.5418 \AA)$. Energy-dispersive X-ray spectroscopy (EDS) analysis was performed using "JEOL JSM-6340F" field emission scanning electron microscope with an accelerating voltage of $20 \mathrm{kV}$, to determine the chemical composition of $\mathrm{SnS}$ nanoflakes. Transmission electron microscope (TEM) images and diffraction patterns were obtained using TEM JEOL 2100F operating at $200 \mathrm{kV}$.

The prepared SnS powder was pressed into pellet in a uniaxial hydraulic press using a dye of $10 \mathrm{~mm}$ diameter and applying a pressure of five ton per $\mathrm{mm}^{2}$. The thickness of the prepared pellet was $1 \mathrm{~mm}$. For proper physical strength and removal of pores pellet was sintered at $200{ }^{\circ} \mathrm{C}$ for $2 \mathrm{~h}$. Pellet was removed from furnace and allowed to cool down naturally before using it as sensor. Electrical contacts were made with the help of conducting silver paste on same side of pellet. The distance between the contacts was $2 \mathrm{~mm}$. After forming the contacts, the pellet was cured at $100{ }^{\circ} \mathrm{C}$ for $2 \mathrm{~h}$ for better adhesion of silver paste with $\mathrm{SnS}$ nanoflakes.
Table 1 X-ray diffraction intensities and preferred orientation factor for orthorhombic phase of SnS nanoflakes

SnS

\begin{tabular}{rrrrrl}
\hline$h$ & $k$ & $l$ & \multicolumn{1}{c}{$I_{\text {xrd }}$} & $I_{\text {card }}$ & Texture coefficient \\
\hline 1 & 1 & 0 & 5513 & 32 & 0.522764185 \\
1 & 2 & 0 & 17366 & 67 & 0.786489277 \\
0 & 2 & 1 & 18681 & 70 & 0.809785307 \\
1 & 0 & 1 & 12107.7 & 53 & 0.693192083 \\
1 & 1 & 1 & 26314 & 100 & 0.798462791 \\
$\mathbf{0}$ & $\mathbf{4}$ & $\mathbf{0}$ & $\mathbf{6 0 5 3 8}$ & $\mathbf{6 9}$ & $\mathbf{2 . 6 6 2 2 3 7 4 6 1}$ \\
1 & 3 & 1 & 12383 & 40 & 0.939363527 \\
2 & 1 & 0 & 3159 & 19 & 0.504503097 \\
1 & 4 & 1 & 11323 & 30 & 1.145270474 \\
0 & 0 & 2 & 7379 & 26 & 0.861176112 \\
2 & 1 & 1 & 6573 & 27 & 0.738699287 \\
1 & 5 & 1 & 8163 & 18 & 1.376084501 \\
1 & 2 & 2 & 3689 & 14 & 0.799555162 \\
0 & 6 & 1 & 5004 & 13 & 1.16799709 \\
0 & 4 & 2 & 463 & 18 & 0.078050609 \\
2 & 5 & 0 & 1569 & 4 & 1.190229648 \\
2 & 5 & 1 & 3159 & 15 & 0.639037257 \\
0 & 8 & 0 & 3689 & 7 & 1.599110324 \\
2 & 3 & 2 & 2374 & 8 & 0.900447796 \\
0 & 8 & 1 & 1039 & 2 & 1.576352587 \\
1 & 6 & 2 & 1590 & 5 & 0.964928051 \\
2 & 7 & 0 & 805 & 3 & 0.814221259 \\
1 & 1 & 3 & 2629 & 6 & 1.329557572 \\
1 & 3 & 3 & 1090 & 3 & 1.102485929
\end{tabular}


The gas sensing characteristics of the SnS nanoflakes sensor were measured using a probe station with closed chamber. The temperature of base of probe station (Materials Development Corporation USA, Cryogenic Probe Station Model 441), on which sample was placed, could be varied as desired with error $\pm 1{ }^{\circ} \mathrm{C}$. The current-voltage $(I-V)$ characteristics, response and recovery time curves were measured using Agilent 4156C parameter analyzer.

\section{Results and discussion}

XRD spectrum of SnS nanoflakes (Fig. 1(a)) shows formation of pure orthorhombic SnS nanoflakes with space group Pbnm (62). All diffraction peaks in Fig. 1(a) match with those in the PDF card number 00-033-1375. The lattice constant parameters calculated from the XRD spectrum are $a=4.298 \AA, b=11.201 \AA$ and $c=3.977 \AA$. The volume of cell is $193.489 \AA^{3}$. The calculated lattice constant parameters and cell volume agree well with the values given in the PDF card number 00-033-1375 $(a=4.334 \AA$, $b=11.200 \AA, c=3.987 \AA$ and cell volume $\left.=193.529 \AA^{3}\right)$. The degree of preferred orientation of different crystalline planes can be obtained from the XRD pattern by calculating texture coefficient $\left(\mathrm{TC}_{h k l}\right)$ given by: $:^{24}$

$$
\mathrm{TC}_{h k l}=\left[\frac{I_{h k l}}{I_{\mathrm{r}_{h k l}}}\right] /\left[\frac{1}{N} \sum_{N} \frac{I_{h k l}}{I_{\mathrm{r}_{h k l}}}\right]
$$

where $I_{\mathrm{r}_{h k l}}$ indicates the intensity of reference pattern (PDF), $I_{h k l}$ is the intensity obtained from XRD pattern of SnS nanoflakes and $N$ is number of diffraction peaks taken into account. This equation shows that texture coefficient of each crystallographic plane is unity for a randomly distributed powder sample. However for preferentially oriented plane it is greater than unity. ${ }^{25} \mathrm{TC}_{h k l}$ 's calculated for SnS nanoflakes are shown in the Table 1. From the Table 1, it can be seen that the texture
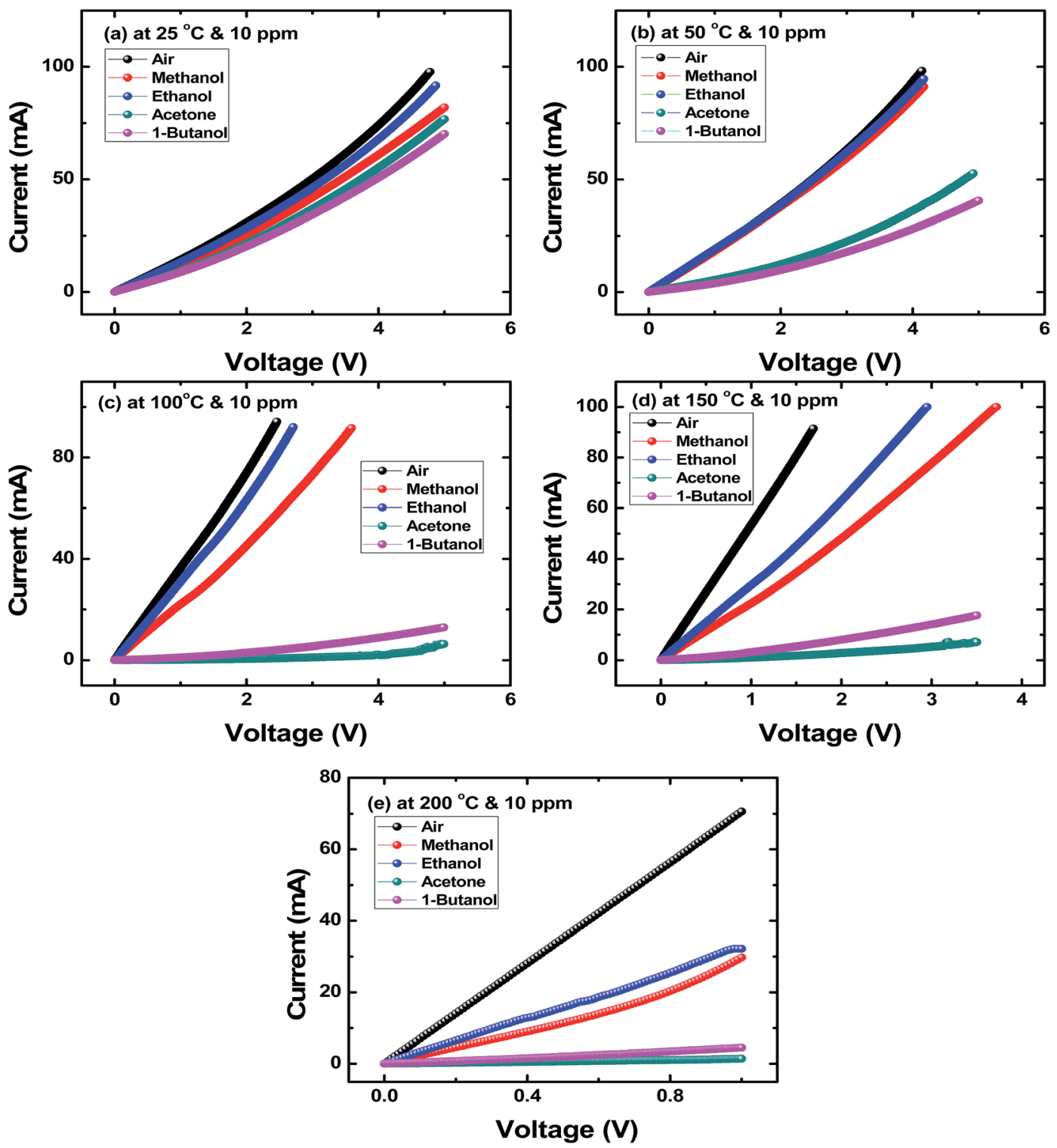

Fig. 2 I-V characteristics SnS nanoflakes in air, methanol, ethanol, acetone and 1-butanol at (a) $25^{\circ} \mathrm{C}$ (b) $50{ }^{\circ} \mathrm{C}$ (c) $100{ }^{\circ} \mathrm{C}$ (d) $150{ }^{\circ} \mathrm{C}$ (e) $200{ }^{\circ} \mathrm{C}$. 
coefficient value (2.66) for (040) plane is highest indicating that it is more preferably oriented.

Fig. 1(b) shows the result of the chemical analysis performed by EDS. Presence of Sn and S peaks only in this spectrum also confirm purity of prepared SnS nanoflakes. Fig. 1(c) shows the low resolution TEM image of SnS nanoflakes. It can be seen that many nanoflakes are present on the copper grid and are randomly placed. Fig. 1(d) shows the HRTEM image of single SnS nanoflake clearly showing that it is polycrystalline. Top and middle inset to Fig. 1(d) shows well resolved lattice planes with (interplanar spacings) $d$-spacing $0.342 \mathrm{~nm}$ and $0.404 \mathrm{~nm}$. These $d$-spacings correspond to lattice planes (110) and (120) of SnS nanoflakes respectively. The bottom inset to the Fig. 1(d) (diffraction pattern of $\mathrm{SnS}$ nanoflakes obtained in TEM) is another evidence for the polycrystalline nature of the SnS nanoflakes.
Resistive type SnS nanoflakes sensors were tested for Acetone and alcohols sensing. The $\mathrm{SnS}$ nanoflakes response was measured from $25{ }^{\circ} \mathrm{C}$ to $200{ }^{\circ} \mathrm{C}$. The concentration of gas was fixed to $10 \mathrm{ppm}$ in all of these experiments.

Fig. 2(a-e) show $I-V$ characteristics of $\mathrm{SnS}$ nanoflakes sensor in air, acetone and alcohols at different temperatures in order to calculate the response for these gases. The $I-V$ characteristics are nonlinear. It is noted that at all temperatures when an acetone or an alcohol is injected into test chamber the value of the current decreases indicating an increase in resistance of the SnS nanoflakes sensor. However, the minimum decrease in current is for ethanol and maximum decrease in current is for 1butanol at temperatures $25{ }^{\circ} \mathrm{C}$ and $50{ }^{\circ} \mathrm{C}$ (Fig. 2(a and b)). From $100{ }^{\circ} \mathrm{C}$ to $200{ }^{\circ} \mathrm{C}$ (Fig. 2(c-e)) the minimum decrease in current is for ethanol and maximum decrease in current is for acetone.
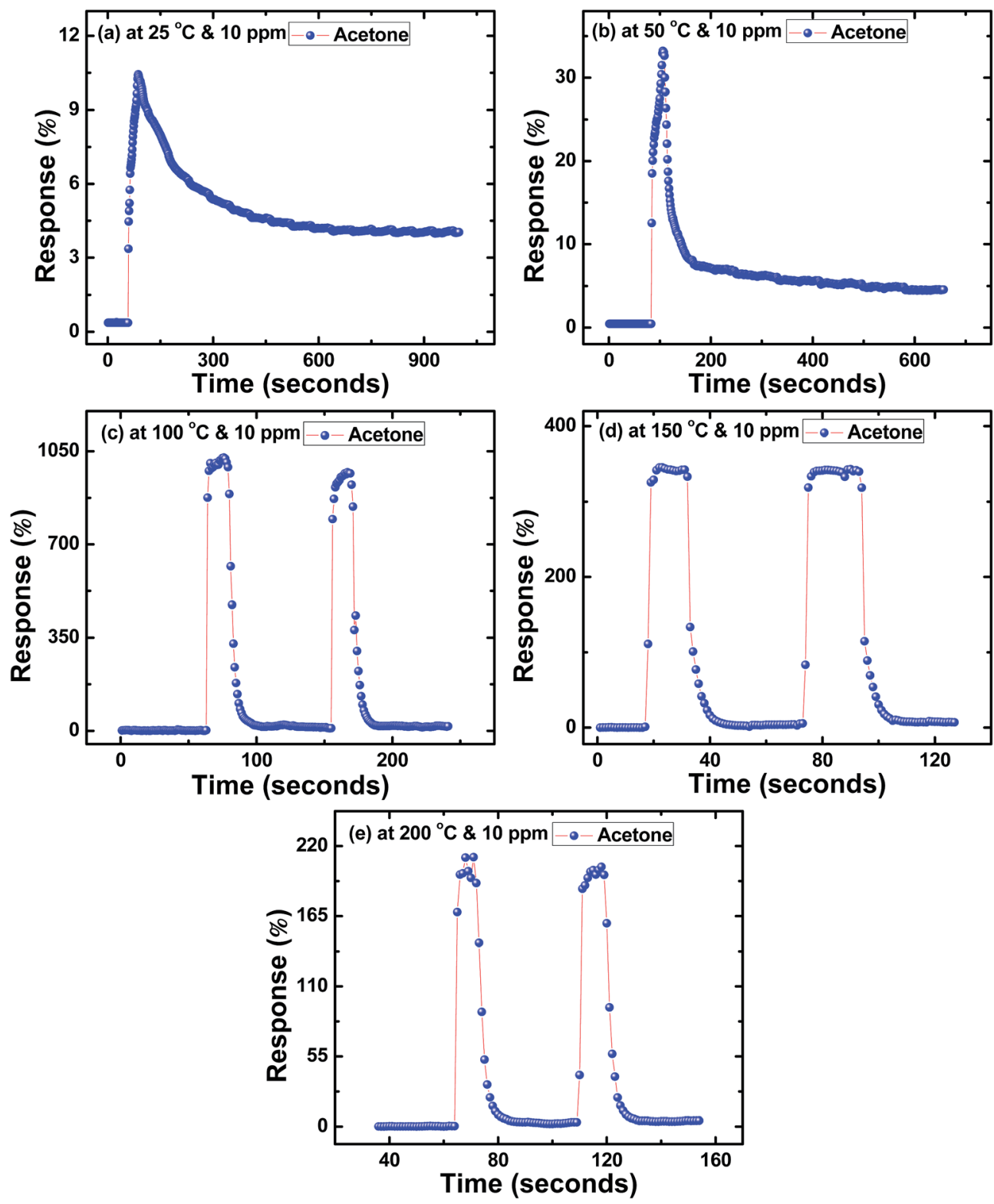

Fig. 3 Response curves of SnS nanoflakes in acetone at (a) $25^{\circ} \mathrm{C}$ (b) $50^{\circ} \mathrm{C}$ (c) $100{ }^{\circ} \mathrm{C}$ (d) $150{ }^{\circ} \mathrm{C}$ (e) $200{ }^{\circ} \mathrm{C}$. 
In order to study reversibility characteristics of SnS nanoflakes sensors, sensors were exposed to $10 \mathrm{ppm}$ of acetone or alcohol and air alternately for two or more cycles. ${ }^{12}$ From these measurements, the response and recovery times of SnS nanoflakes were calculated. Fig. 3(a-e) show the response time $\left(t_{\text {(air-to-acetone) }}\right)$ and recovery time $\left(t_{\text {(acetone-to-air) }}\right)$ of SnS nanoflakes sensor for $10 \mathrm{ppm}$ concentration of acetone at different temperatures. Fig. 3(c-e) clearly show the good reversibility of SnS nanoflakes sensor for two complete cycles.

Similarly, Fig. 4(a-e) to $6(\mathrm{a}-\mathrm{e})$ show the response time $\left(t_{(\text {air-to-acetone })}\right)$ and recovery time $\left(t_{\text {(acetone-to-air) }}\right)$ of SnS nanoflakes sensors for $10 \mathrm{ppm}$ concentration of each alcohol from $25{ }^{\circ} \mathrm{C}$ to $200{ }^{\circ} \mathrm{C}$. Fig. 4(c and d) and 5(c and d) show the good reversibility of $\mathrm{SnS}$ nanoflakes sensor for two complete cycles while Fig. 4(e) and 5(e) show reversibility for four complete cycles. Also Fig. 6(d and e) show good reversibility for two complete cycles.

Generally, in all cases, there is improvement in response and recovery time of the sensor as temperature is increased from $25^{\circ} \mathrm{C}$ to $200^{\circ} \mathrm{C}$. This improvement is larger at $100^{\circ} \mathrm{C}$ and above. It can be noted that improvement in recovery times is more as compared to improvement in response time. The response and recovery times calculated from these graphs are shown in the Fig. 7(a and b).

The gas sensor response $(S)$ is defined as:

$$
\begin{aligned}
& S=\left(\frac{R_{\mathrm{g}}}{R_{\mathrm{a}}}-1\right) \times 100 \% \text { for } R_{\mathrm{g}}>R_{\mathrm{a}} \\
& S=\left(\frac{R_{\mathrm{a}}}{R_{\mathrm{g}}}-1\right) \times 100 \% \text { for } R_{\mathrm{a}}>R_{\mathrm{g}}
\end{aligned}
$$
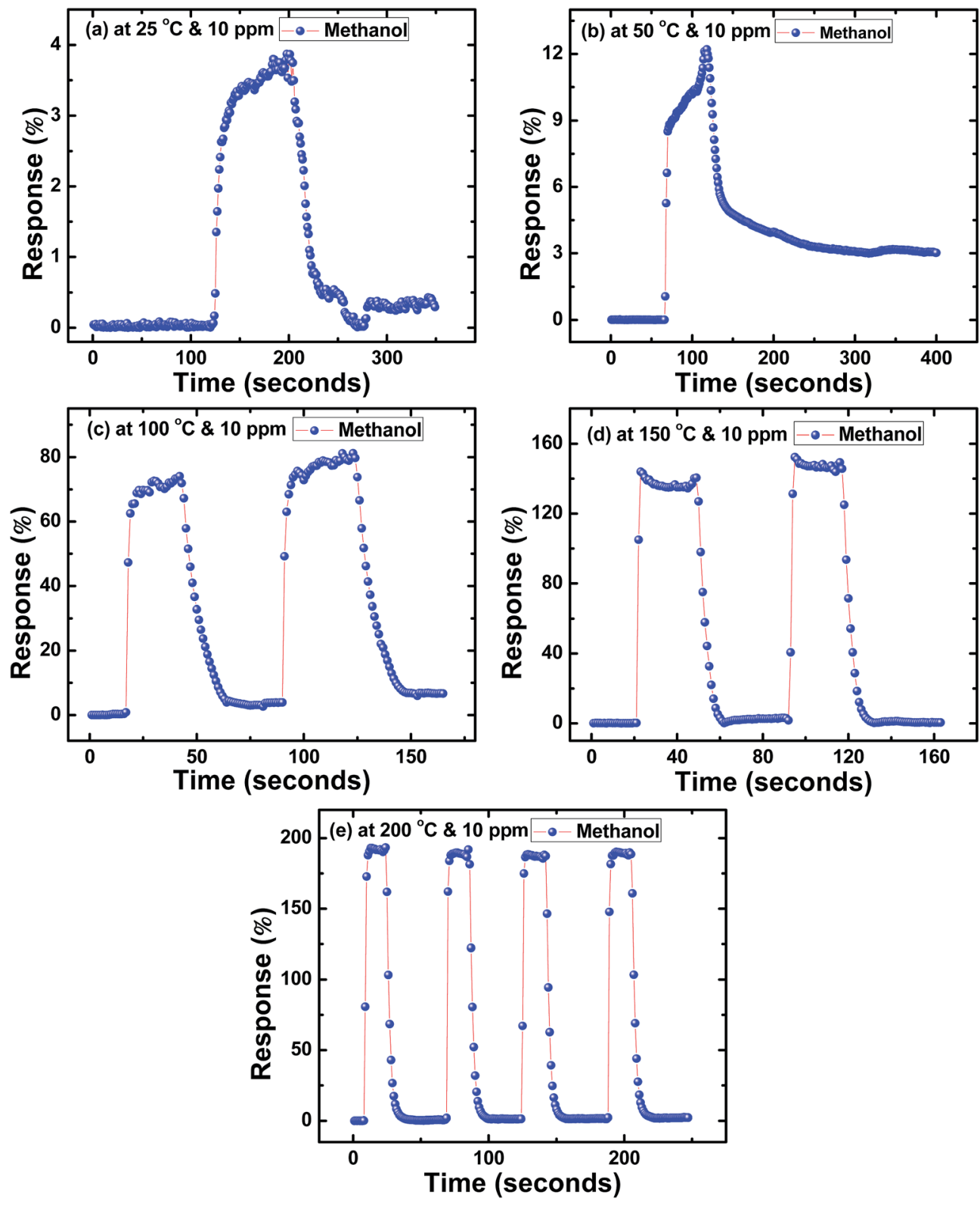

Fig. 4 Response curves of SnS nanoflakes in methanol at (a) $25^{\circ} \mathrm{C}$ (b) $50^{\circ} \mathrm{C}$ (c) $100{ }^{\circ} \mathrm{C}$ (d) $150{ }^{\circ} \mathrm{C}$ (e) $200{ }^{\circ} \mathrm{C}$. 

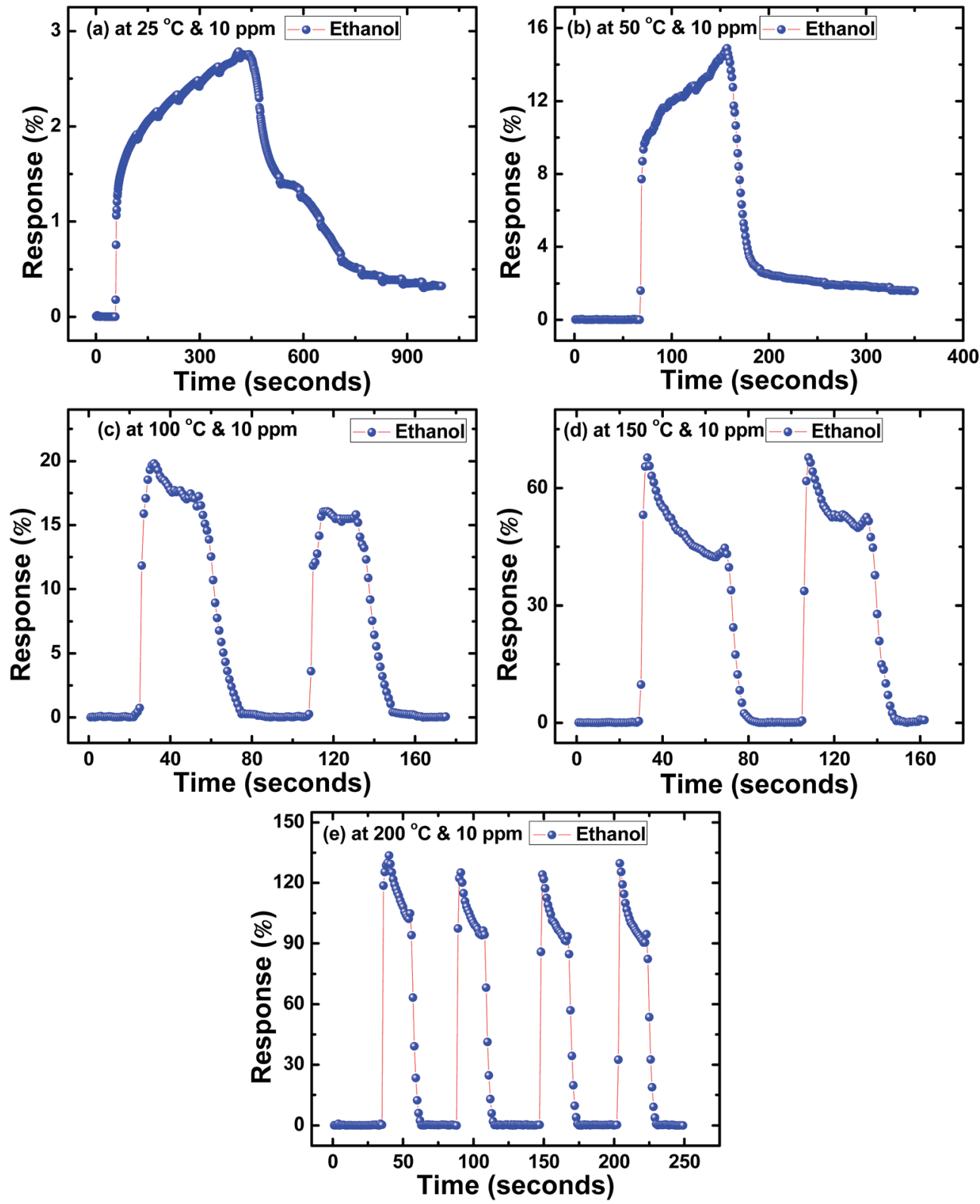

Fig. 5 Response curves of SnS nanoflakes in ethanol at (a) $25^{\circ} \mathrm{C}$ (b) $50^{\circ} \mathrm{C}$ (c) $100^{\circ} \mathrm{C}$ (d) $150{ }^{\circ} \mathrm{C}$ (e) $200^{\circ} \mathrm{C}$.

where $R_{\mathrm{a}}$ and $R_{\mathrm{g}}$ are the steady-state resistances in air and gas respectively. From the definition of the eqn (2) and (3), it is clear that $S$ is zero for the gases that leave resistance unchanged. $S$ is positive for reducing gases and negative for oxidizing gases. ${ }^{\mathbf{1 1}}$ The histogram of Fig. 7(c) shows the calculated response for $\mathrm{SnS}$ nanoflakes for all gases at different temperature with $10 \mathrm{ppm}$ fixed concentration. For methanol the value of the response increases with increase in temperature and is maximum at $200^{\circ} \mathrm{C}$. Similarly, for ethanol the value of the response also increases with increase in temperature and is maximum at $200{ }^{\circ} \mathrm{C}$. But for acetone and 1butanol when temperature increases from $25{ }^{\circ} \mathrm{C}$ to $100{ }^{\circ} \mathrm{C}$, the value of the response increases and then decreases as the temperature increases to $200{ }^{\circ} \mathrm{C}$. The response of SnS nanoflakes is maximum for acetone at $100{ }^{\circ} \mathrm{C}$ as compared to methanol, ethanol and 1-butanol at all temperatures.
The temperature dependence of the sensor response is generally controlled by two parameters: the reaction rate between the adsorbed oxygen ions with acetone and alcohol molecules and the electron density of the sensor. The reaction rate coefficient and hole density increases exponentially with increasing temperature. On the other hand, the sensor response is proportional to the reaction rate coefficient and inversely proportional to the electron density. These two parameters compete each other and result in a maximum sensor response at the optimal operating temperature. ${ }^{26}$ From Fig. $7(\mathrm{c})$ it is suggested that optimal operating temperature (for the temperature range $25^{\circ} \mathrm{C}$ to $200{ }^{\circ} \mathrm{C}$ ) for acetone and 1-butanol is $100{ }^{\circ} \mathrm{C}$.

To explain gas sensing results a proposed gas-sensing mechanism is shown in the schematic diagram (Fig. 8). SnS is a p-type semiconductor. ${ }^{27}$ When SnS nanoflakes are exposed to 

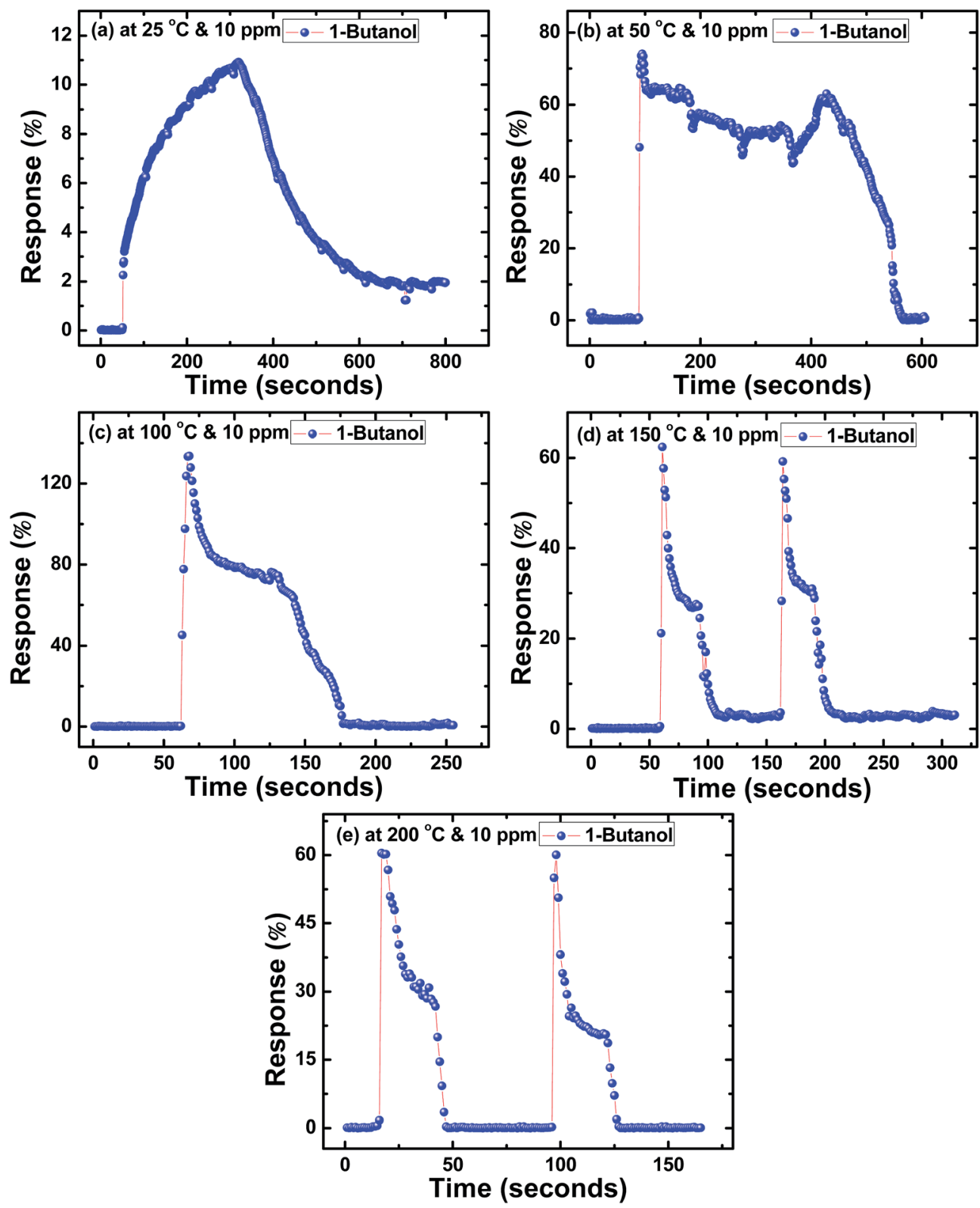

Fig. 6 Response curves of SnS nanoflakes in 1-butanol at (a) $25^{\circ} \mathrm{C}$ (b) $50^{\circ} \mathrm{C}$ (c) $100{ }^{\circ} \mathrm{C}$ (d) $150{ }^{\circ} \mathrm{C}$ (e) $200{ }^{\circ} \mathrm{C}$.

air, they adsorb oxygen from air. Wolkenstein's model ${ }^{28}$ states that adsorbed neutral oxygen molecules $(\mathrm{O})_{\text {ads }}$ on surface of the semiconductor are partially ionized into $\mathrm{O}^{-}, \mathrm{O}_{2}{ }^{-}$or $\mathrm{O}^{2-}$ ions by attracting electron from valence band of the semiconductor at various temperatures as shown below: ${ }^{29}$

$$
\begin{gathered}
\left(\mathrm{O}_{2}\right)_{\mathrm{gas}} \leftrightarrow\left(\mathrm{O}_{2}\right)_{\mathrm{ads}} \\
\left(\mathrm{O}_{2}\right)_{\mathrm{ads}}+\mathrm{e}^{-} \leftrightarrow\left(\mathrm{O}_{2}{ }^{-}\right)_{\mathrm{ads}},\left(25-150{ }^{\circ} \mathrm{C}\right) \\
\left(\mathrm{O}_{2}{ }^{-}\right)_{\mathrm{ads}}+\mathrm{e}^{-} \leftrightarrow 2\left(\mathrm{O}^{-}\right)_{\mathrm{ads}},\left(150-200^{\circ} \mathrm{C}\right)
\end{gathered}
$$

Reduction of these electrons from valence band will change charge status of surface of the sensor producing a positive accumulation zone by holes and a surface negative charge layer which covers the whole surface of the sensor [Fig. 8]. Therefore over all resistance of the sensor decreases and constant value of the resistance is achieved after saturation. ${ }^{30}$ Now, when the sensor is exposed to reducing gases such as alcohols and acetone their possible reactions with the adsorbed oxygen can be explained as follows:

For alcohols, dehydrogenation of alcohols by the adsorbed oxygen ions may be responsible for the increase in resistance of the sensor. In case of methanol, as its molecule approaches the sensor with adsorbed oxygen, it can lose one $\mathrm{H}$ from $\mathrm{CH}_{3}$ group and that of $\mathrm{OH}$ group, due to the attraction with adsorbed oxygen, resulting in the formation of water molecule. Water molecule desorbs releasing one electron into the material. Thus the dehydrogenated methanol turns into formic acid (25-150 


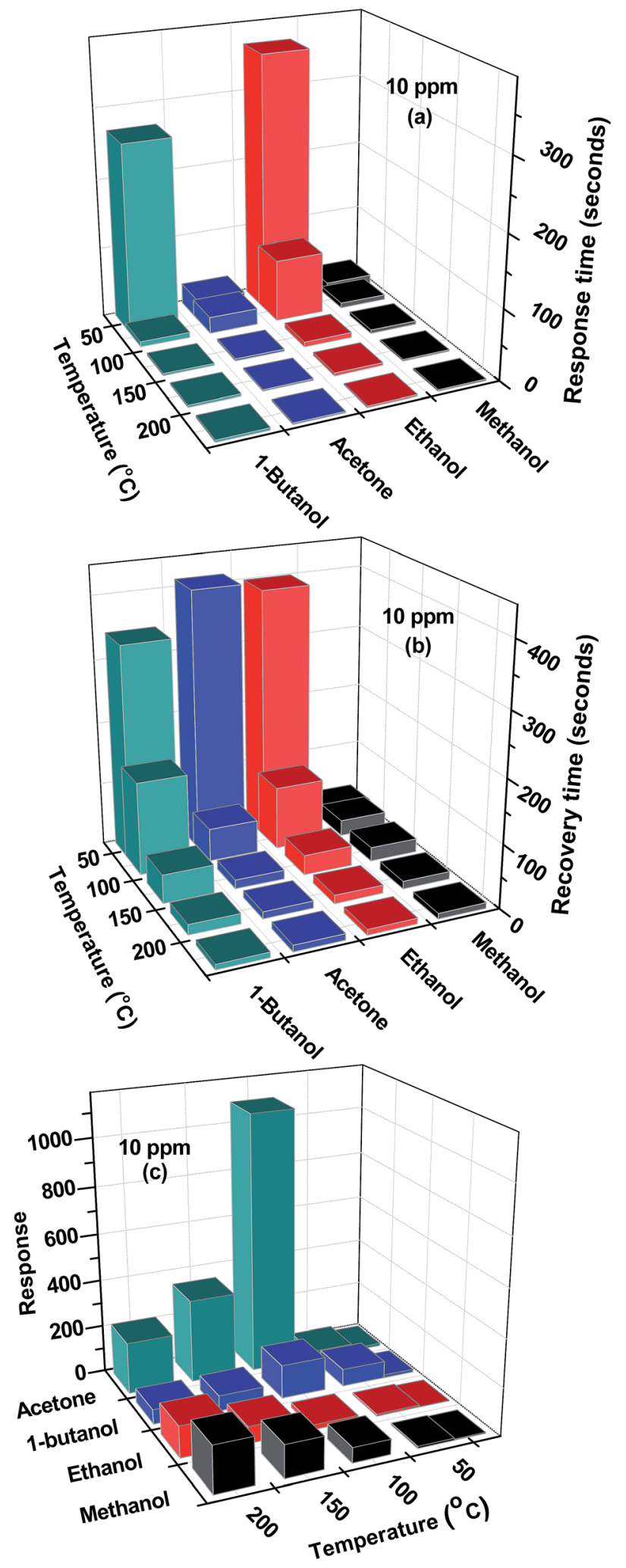

Fig. 7 Variation of SnS nanoflakes in (a) response time (b) recovery time (c) response with acetone, methanol, ethanol and 1-butanol as a function of temperature.
${ }^{\circ} \mathrm{C}$ ) and formaldehyde $\left(150-200{ }^{\circ} \mathrm{C}\right)$, the reaction schematics being the following:

$$
\begin{gathered}
\mathrm{CH}_{3} \mathrm{OH}+\mathrm{O}_{2}^{-} \rightarrow \mathrm{HCOOH}+\mathrm{H}_{2} \mathrm{O}+\mathrm{e}^{-},\left(25-150{ }^{\circ} \mathrm{C}\right) \\
\mathrm{CH}_{3} \mathrm{OH}+\mathrm{O}^{-} \rightarrow \mathrm{CH}_{2} \mathrm{O}+\mathrm{H}_{2} \mathrm{O}+\mathrm{e}^{-},(150-200 \mathrm{C})
\end{gathered}
$$

A similar process can occur in case of ethanol, which would turn into ethanoic acid $\left(25-150^{\circ} \mathrm{C}\right)$ and acetaldehyde (150-200 ${ }^{\circ} \mathrm{C}$ ), and in case of 1-butanol, which would turn into butyric acid $\left(25-150{ }^{\circ} \mathrm{C}\right)$ and butyraldehyde $\left(150-200{ }^{\circ} \mathrm{C}\right)$, as in the following reaction schematics:

$$
\begin{aligned}
& \mathrm{CH}_{3} \mathrm{CH}_{2} \mathrm{OH}+\mathrm{O}_{2}^{-} \rightarrow \mathrm{CH}_{3} \mathrm{COOH}+\mathrm{H}_{2} \mathrm{O}+\mathrm{e}^{-},\left(25-150{ }^{\circ} \mathrm{C}\right) \\
& \mathrm{CH}_{3} \mathrm{CH}_{2} \mathrm{OH}+\mathrm{O}^{-} \rightarrow \mathrm{CH}_{3} \mathrm{COH}+\mathrm{H}_{2} \mathrm{O}+\mathrm{e}^{-},\left(150-200{ }^{\circ} \mathrm{C}\right) \\
& \mathrm{CH}_{3} \mathrm{CH}_{2} \mathrm{CH}_{2} \mathrm{CH}_{2} \mathrm{OH}+\mathrm{O}_{2}^{-} \rightarrow \\
& \mathrm{CH}_{3} \mathrm{CH}_{2} \mathrm{CH}_{2} \mathrm{COOH}+\mathrm{H}_{2} \mathrm{O}+\mathrm{e}^{-},\left(25-150{ }^{\circ} \mathrm{C}\right) \\
& \mathrm{CH}_{3} \mathrm{CH}_{2} \mathrm{CH}_{2} \mathrm{CH}_{2} \mathrm{OH}+\mathrm{O}^{-} \rightarrow \\
& \mathrm{CH}_{3} \mathrm{CH}_{2} \mathrm{CH}_{2} \mathrm{COH}+\mathrm{H}_{2} \mathrm{O}+\mathrm{e}^{-},\left(150-200^{\circ} \mathrm{C}\right)
\end{aligned}
$$

Hence, the adsorption of alcohols on the surface of SnS nanoflakes will cause electron-hole pair annihilation, i.e., it will decrease the hole concentration that decreases the net surface negative charge and increases the overall resistance of SnS nanoflakes sensor. ${ }^{13,30,31}$

For acetone, possible reactions of acetone with adsorbed oxygen is shown as below:

From $25{ }^{\circ} \mathrm{C}$ to $150{ }^{\circ} \mathrm{C}$

$$
\begin{aligned}
2 \mathrm{CH}_{3} \mathrm{COCH}_{3} \text { (gas) }+\mathrm{O}_{2}^{-} & \rightarrow 2 \mathrm{CH}_{3} \mathrm{CO}^{+}+2 \mathrm{CH}_{3} \mathrm{O}^{-}+\mathrm{e}^{-} \\
\mathrm{CH}_{3} \mathrm{CO}^{+} & \rightarrow \mathrm{CH}_{3}^{+}+\mathrm{CO} \\
2 \mathrm{CO}+\mathrm{O}_{2}^{-} & \rightarrow 2 \mathrm{CO}_{2}+\mathrm{e}^{-}
\end{aligned}
$$

From $\left(150-200{ }^{\circ} \mathrm{C}\right)$

$$
\begin{aligned}
\mathrm{CH}_{3} \mathrm{COCH}_{3} \text { (gas) }+\mathrm{O}^{-} & \rightarrow \mathrm{CH}_{3} \mathrm{CO}^{+}+\mathrm{CH}_{3} \mathrm{O}^{-}+\mathrm{e}^{-} \\
\mathrm{CH}_{3} \mathrm{CO}^{+} & \rightarrow \mathrm{CH}_{3}^{+}+\mathrm{CO} \\
\mathrm{CO}+\mathrm{O}^{-} & \rightarrow \mathrm{CO}_{2}+\mathrm{e}^{-}
\end{aligned}
$$

Similarly, the adsorption of acetone on the surface of SnS nanoflakes will cause electron-hole pair annihilation, i.e., it will decrease the hole concentration which decreases the net surface negative charge and increases the overall resistance of SnS nanoflakes sensor. As per suggested reaction of acetone with adsorbed oxygen more electrons are being produced as compared to alcohols. That may be one of the reason that the response of acetone is relatively high as compared to alcohols at all temperatures at fixed concentration.

The selectivity might be related to the different optimal operating temperatures of the sensor for different gases. The 
0

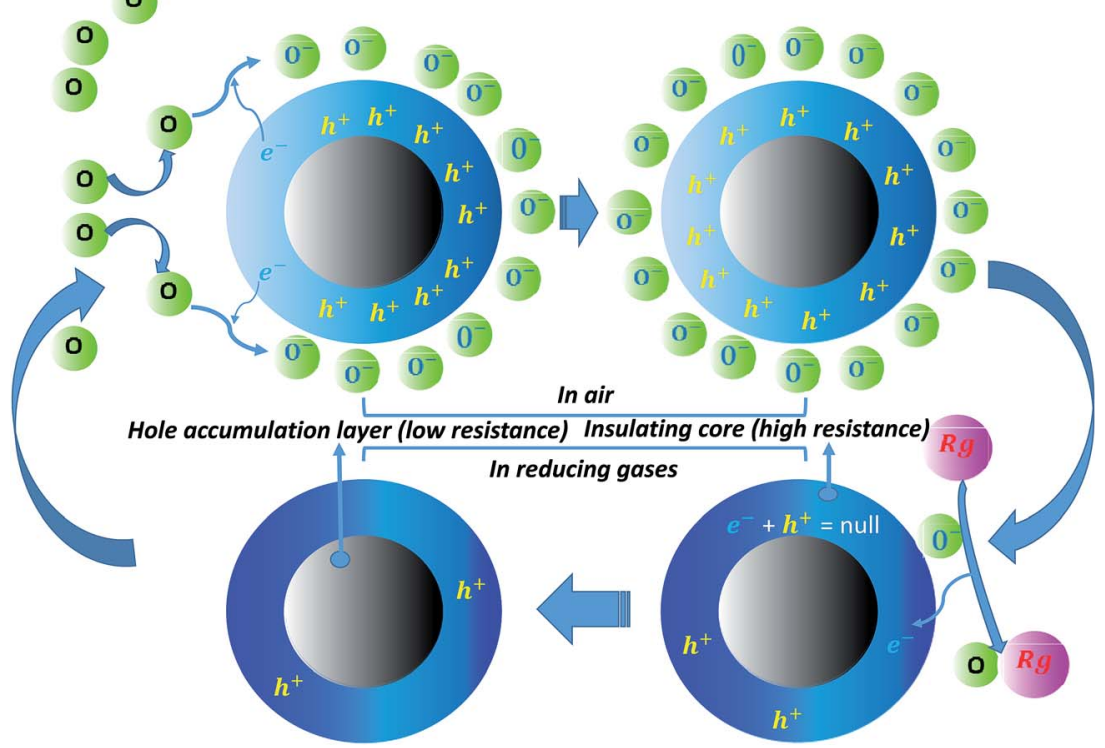

Fig. 8 Schematic diagram of gas sensing mechanism for $\mathrm{p}$-type SnS nanoflakes sensor $\left(R_{\mathrm{g}}\right.$ shows reducing gas).

response of a sensor would depend strongly on the type of gas at different temperatures because different gases have different activation energies for adsorption, desorption and reaction on the semiconductor. ${ }^{32}$

For acetone, we compare our results with those given in Table 1 of ref. 33, Table II of ref. 34, Table 1 of ref. 35 and Table 1 of ref. 36. SnS nanoflakes sensor has high response $(\sim 1000 \%)$ and fast response time ( $3 \mathrm{~s})$ and recovery time (14 s) at relatively lower optimum temperature $100{ }^{\circ} \mathrm{C}$.

For methanol, we compare our results with those given in Table 1 of ref. 37, Table IV of ref. 29, Table 1 of ref. 38 and Table 1 of ref. 39. SnS nanoflakes sensor has high response $(\sim 190 \%)$
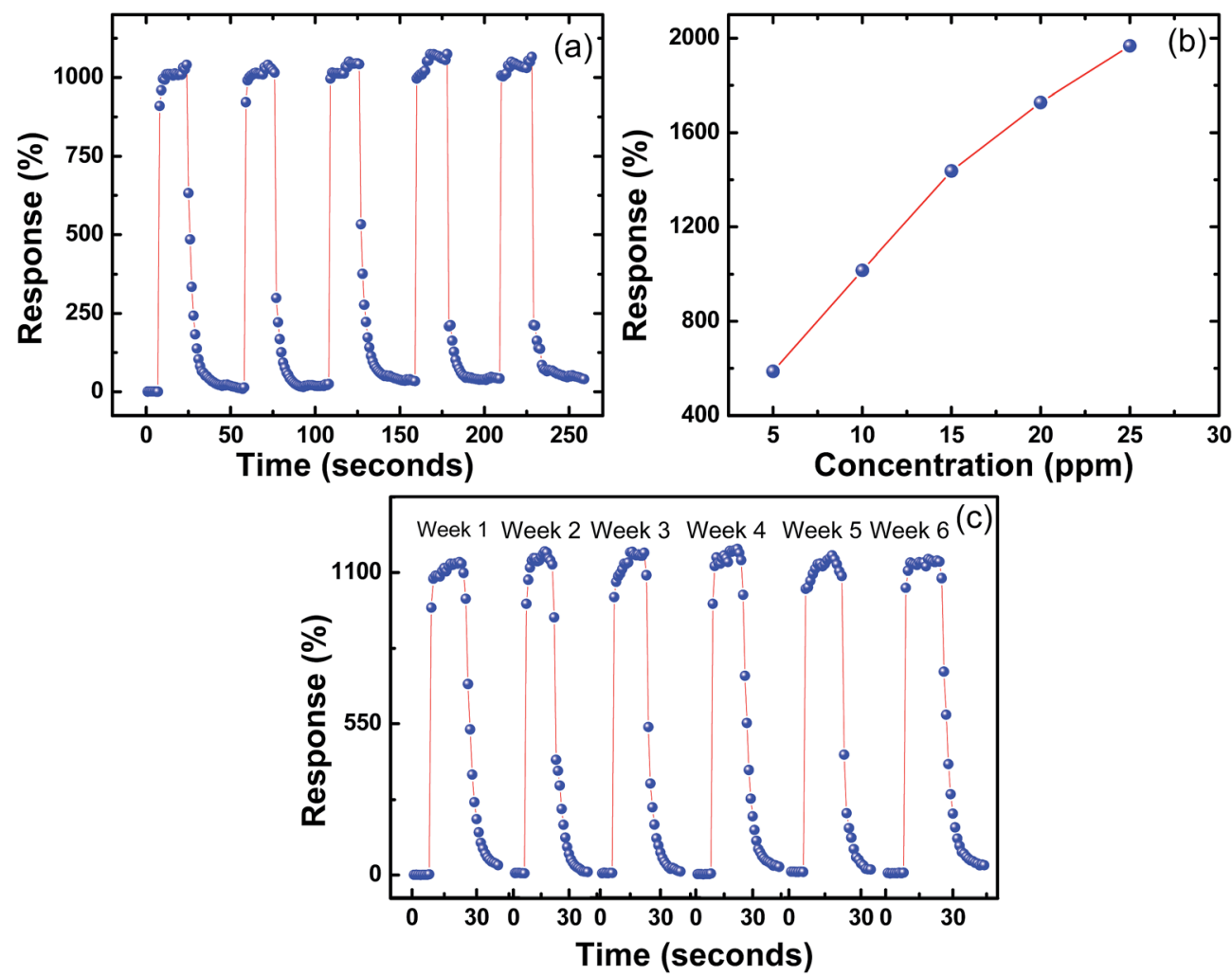

Fig. $9 \mathrm{SnS}$ nanoflakes sensor characteristics at $100{ }^{\circ} \mathrm{C}$ (a) repetitive response for $10 \mathrm{ppm}$ acetone concentration indicating reproducibility (b) dependence of response on acetone concentration (c) long-term stability of the sensor over 6 weeks with 10 ppm acetone concentration. 
and fast response time ( $2 \mathrm{~s})$ and recovery time (9s) at temperature $200{ }^{\circ} \mathrm{C}$.

For ethanol, we compare our results with those given in Tables $1 \& 2$ of ref. 40, Table 2 of ref. 41, and Table 2 of ref. 42 . SnS nanoflakes sensor has high response $(\sim 130 \%)$ and fast response time ( $2 \mathrm{~s})$ and recovery time ( $9 \mathrm{~s})$ at temperature $200{ }^{\circ} \mathrm{C}$.

For 1-butanol, we compare our results with those given in Table 1 of ref. 43, and Table 2 of ref. 44. SnS nanoflakes sensor has high response $(\sim 140 \%)$ and fast response time $(3 \mathrm{~s})$ and recovery time (45 s) at low optimum temperature $100{ }^{\circ} \mathrm{C}$.

As SnS nanoflakes exhibited high values of response ( $\sim 1000 \%$ ) for acetone as compared to methanol, ethanol, and 1butanol. Therefore other characteristics of the sensor such as reproducibility, effect of concentration of acetone and longterm stability were studied for acetone only at the optimum operating temperature $100{ }^{\circ} \mathrm{C}$. Fig. 9(a) shows five complete response and recovery cycles of $\mathrm{SnS}$ nanoflakes sensor at $100{ }^{\circ} \mathrm{C}$ for $10 \mathrm{ppm}$ acetone. Figure clearly indicates good reproducibility of the sensor with slight variation in response $(<3 \%)$. Fig. 9(b) shows the response of SnS nanoflakes sensor at $100{ }^{\circ} \mathrm{C}$ for different acetone concentrations. A linear increase in response is observed as acetone concentration changes from $5 \mathrm{ppm}$ to $25 \mathrm{ppm}$. To test the long-term stability of the SnS nanoflakes sensor, it was kept in air for 6 weeks at room temperature and the response of the sensor was tested every week at $100{ }^{\circ} \mathrm{C}$ with $10 \mathrm{ppm}$ acetone concentration. Fig. 9(c) shows the results obtained during these measurements. Almost negligible change $(<4 \%)$ in the response of $\mathrm{SnS}$ nanoflakes sensor was observed over 6 weeks, conforming good stability of the sensor.

\section{Conclusions}

In this work, the SnS nanoflakes were prepared using a simple conventional solid state reaction method. These nanoflakes were characterized by XRD, TEM, and EDS. The gas sensing properties of SnS nanoflakes were investigated at different temperatures. The SnS nanoflakes exhibited excellent gas sensing properties especially for acetone with maximum response $\sim 1000 \%$ at $100{ }^{\circ} \mathrm{C}$ with fast response and recovery time. At optimum operating temperature $\left(100{ }^{\circ} \mathrm{C}\right)$, the $\mathrm{SnS}$ nanoflakes sensor showed good stability and reproducibility for acetone. The response and recovery characteristics of the SnS nanoflakes were quick and reproducible. Therefore, this study demonstrates the possibility of utilization of SnS nanoflakes for the detection of alcohols and acetone and possibly for detection of diabetes.

\section{Acknowledgements}

M. F. Afsar would like to acknowledge the Higher Education Commission of Pakistan for the financial support through International Research Initiative Program (IRSIP). Authors are thankful to Dr Tay Yee Yan of Nanyang Technological University Singapore for his help in TEM analysis. M. A. Rafiq would like to acknowledge Higher Education Commission for financial support under National Research Program for Universities (NRPU Project No. 3662).

\section{References}

1 A. Ghazali, Z. Zainal, M. Z. Hussein and A. Kassim, Cathodic electrodeposition of $\mathrm{SnS}$ in the presence of EDTA in aqueous media, Sol. Energy Mater. Sol. Cells, 1998, 55, 237-249.

2 A. Muthuvinayagama and B. Viswanathanb, Hydrothermal synthesis and LPG sensing ability of SnS nanomaterial, Indian J. Chem., 2015, 54, 155-160.

3 J. Vidal, S. Lany, M. d'Avezac, A. Zunger, A. Zakutayev, J. Francis and J. Tate, Band-structure, optical properties, and defect physics of the photovoltaic semiconductor SnS, Appl. Phys. Lett., 2012, 100, 032104.

4 I. Kherchachi, A. Attaf, H. Saidi, A. Bouhdjer, H. Bendjedidi, Y. Benkhetta and R. Azizi, Structural, optical and electrical properties of $\mathrm{Sn}_{x} \mathrm{~S}_{y}$ thin films grown by spray ultrasonic, $J$. Semicond., 2016, 37, 032001.

5 S. H. Chaki, M. D. Chaudhary and M. Deshpande, SnS thin films deposited by chemical bath deposition, dip coating and SILAR techniques, J. Semicond., 2016, 37, 053001.

6 N. Koteeswara Reddy, M. Devika, Q. Ahsanulhaq and K. Gunasekhar, Growth of orthorhombic SnS nanobox structures on seeded substrates, Cryst. Growth Des., 2010, 10, 4769-4772.

7 P. Tang, H. Chen, F. Cao, G. Pan, K. Wang, M. Xu and Y. Tong, Nanoparticulate SnS as an efficient photocatalyst under visible-light irradiation, Mater. Lett., 2011, 65, 450452.

8 G. S. Paul, P. Gogoi and P. Agarwal, Structural and stability studies of CdS and SnS nanostructures synthesized by various routes, J. Non-Cryst. Solids, 2008, 354, 2195-2199.

9 H. Tsukigase, Y. Suzuki, M.-H. Berger, T. Sagawa and S. Yoshikawa, Synthesis of SnS nanoparticles by SILAR method for quantum dot-sensitized solar cells, J. Nanosci. Nanotechnol., 2011, 11, 1914-1922.

10 S.-P. Wang, C.-H. Wu and C.-C. Hong, MoS 2 nanosensors fabricated by dielectrophoretic assembly for ultrasensitive and rapid sensing of volatile organic compounds, SENSORS, 2015 IEEE, 2015, pp. 1-4.

11 A. Giberti, D. Casotti, G. Cruciani, B. Fabbri, A. Gaiardo, V. Guidi, C. Malagù, G. Zonta and S. Gherardi, Electrical conductivity of CdS films for gas sensing: Selectivity properties to alcoholic chains, Sens. Actuators, B, 2015, 207, 504-510.

12 S. Bandyopadhyay, B. Chatterjee, P. Nag and A. Bandyopadhyay, Nanocrystalline PbS as Ammonia Gas Sensor: Synthesis and Characterization, CLEAN - Soil, Air, Water, 2015, 43, 1121-1127.

13 A. A. Sagade and R. Sharma, Copper sulphide $\left(\mathrm{Cu}_{x} \mathrm{~S}\right)$ as an ammonia gas sensor working at room temperature, Sens. Actuators, B, 2008, 133, 135-143.

$14 \mathrm{H}$. Karami and S. Babaei, Application of tin sulfide-tin dioxide nanocomposite as oxygen gas sensing agent, Int. J. Electrochem. Sci., 2013, 8, 12078. 
15 A. Gaiardo, B. Fabbri, V. Guidi, P. Bellutti, A. Giberti, S. Gherardi, L. Vanzetti, C. Malagù and G. Zonta, Metal Sulfides as Sensing Materials for Chemoresistive Gas Sensors, Sensors, 2016, 16, 296.

16 A. Giberti, A. Gaiardo, B. Fabbri, S. Gherardi, V. Guidi, C. Malagù, P. Bellutti, G. Zonta, D. Casotti and G. Cruciani, Tin(Iv) sulfide nanorods as a new gas sensing material, Sens. Actuators, B, 2016, 223, 827-833.

17 M. Ahmad, M. Rafiq, Z. Imran, K. Rasool, R. Shahid, Y. Javed and M. Hasan, Charge conduction and relaxation in $\mathrm{MoS}_{2}$ nanoflakes synthesized by simple solid state reaction, $J$. Appl. Phys., 2013, 114, 043710.

18 M. Ahmad, M. Rafiq, K. Rasool, Z. Imran and M. Hasan, Dielectric and transport properties of bismuth sulfide prepared by solid state reaction method, J. Appl. Phys., 2013, 113, 043704.

19 M. Ahmad, M. Rafiq and M. Hasan, Transport characteristics and colossal dielectric response of cadmium sulfide nanoparticles, J. Appl. Phys., 2013, 114, 133702.

20 J.-G. Kang, Y.-D. Ko, K. J. Choi, J.-G. Park and D.-W. Kim, Fabrication of tin monosulfide nanosheet arrays using laser ablation, Appl. Phys. A: Mater. Sci. Process., 2011, 103, 505-510.

$21 \mathrm{M}$. Salavati-Niasari and F. Davar, Shape selective hydrothermal synthesis of tin sulfide nanoflowers based on nanosheets in the presence of thioglycolic acid, J. Alloys Compd., 2010, 492, 570-575.

22 G. Barone, T. G. Hibbert, M. F. Mahon, K. C. Molloy, L. S. Price, I. P. Parkin, A. M. Hardy and M. N. Field, Deposition of tin sulfide thin films from tin(Iv) thiolate precursors, J. Mater. Chem., 2001, 11, 464-468.

23 M. Sousa, A. Da Cunha and P. Fernandes, Annealing of RFmagnetron sputtered $\mathrm{SnS}_{2}$ precursors as a new route for single phase SnS thin films, J. Alloys Compd., 2014, 592, $80-85$.

24 S. Mohamed, $\mathrm{SnO}_{2}$ dendrites-nanowires for optoelectronic and gas sensing applications, J. Alloys Compd., 2012, 510, 119-124.

25 J. Lv, C. Liu, W. Gong, Z. Zi, X. Chen, X. Chen, K. Huang, G. He, S. Shi and X. Song, Study of near white light emission for ZnO thin films grown on silicon substrates, Semicond. Sci. Technol., 2012, 27, 115021.

26 N. Hongsith, E. Wongrat, T. Kerdcharoen and S. Choopun, Sensor response formula for sensor based on $\mathrm{ZnO}$ nanostructures, Sens. Actuators, B, 2010, 144, 67-72.

27 F.-Y. Ran, Z. Xiao, Y. Toda, H. Hiramatsu, H. Hosono and T. Kamiya, n-Type conversion of $\mathrm{SnS}$ by isovalent ion substitution: Geometrical doping as a new doping route, Sci. Rep., 2015, 5, 10428.

28 T. Wolkenstein, Electronic processes on semiconductor surfaces during chemisorption, Springer Science \& Business Media, 2012.

29 N. Banerjee, S. Roy, C. K. Sarkar and P. Bhattacharyya, High dynamic range methanol sensor based on aligned $\mathrm{ZnO}$ nanorods, IEEE Sens. J., 2013, 13, 1669-1676.

30 S. Pokrel, C. Simon, V. Quemener, N. Bârsan and U. Weimer, Investigation of conduction mechanism in $\mathrm{Cr}_{2} \mathrm{O}_{3}$ gas sensing thick films by ac impedance spectroscopy and work function changes measurements, Sens. Actuators, B, 2008, 133, 78-83.

$31 \mathrm{~J} .-\mathrm{W}$. Yoon, J.-K. Choi and J.-H. Lee, Design of a highly sensitive and selective $\mathrm{C}_{2} \mathrm{H}_{5} \mathrm{OH}$ sensor using p-type $\mathrm{Co}_{3} \mathrm{O}_{4}$ nanofibers, Sens. Actuators, B, 2012, 161, 570-577.

32 N. Kılınç, E. Şennik and Z. Öztürk, Fabrication of $\mathrm{TiO}_{2}$ nanotubes by anodization of Ti thin films for VOC sensing, Thin Solid Films, 2011, 520, 953-958.

33 K.-W. Kao, M.-C. Hsu, Y.-H. Chang, S. Gwo and J. A. Yeh, A sub-ppm acetone gas sensor for diabetes detection using $10 \mathrm{~nm}$ thick ultrathin InN FETs, Sensors, 2012, 12, 71577168.

34 N. Banerjee, B. Bhowmik, S. Roy, C. Sarkar and P. Bhattacharyya, Anomalous recovery characteristics of Pd modified $\mathrm{ZnO}$ nanorod based acetone sensor, J. Nanosci. Nanotechnol., 2013, 13, 6826-6834.

35 J. Li, P. Tang, J. Zhang, Y. Feng, R. Luo, A. Chen and D. Li, Facile Synthesis and Acetone Sensing Performance of Hierarchical $\mathrm{SnO}_{2}$ Hollow Microspheres with Controllable Size and Shell Thickness, Ind. Eng. Chem. Res., 2016, 55, 3588-3595.

36 R. Zhang, T. Zhang, T. Zhou, Z. Lou, J. Deng and L. Wang, Fast and real-time acetone gas sensor using hybrid $\mathrm{ZnFe}_{2} \mathrm{O}_{4} / \mathrm{ZnO}$ hollow spheres, RSC Adv., 2016, 6, 6673866744.

37 R. Paulraj, G. K. Mani, L. Nallathambi and J. B. B. Rayappan, A Room Temperature Methanol Vapour Sensor Based on Polyaniline Nanoparticles, J. Nanosci. Nanotechnol., 2016, 16, 8315-8321.

38 S. Wang, P. Wang, Z. Li, C. Xiao, B. Xiao, R. Zhao, T. Yang and $\mathrm{M}$. Zhang, Highly enhanced methanol gas sensing properties by $\mathrm{Pd}_{0.5} \mathrm{Pd}_{3} \mathrm{O}_{4}$ nanoparticle loaded $\mathrm{ZnO}$ hierarchical structures, RSC Adv., 2014, 4, 35375-35382.

39 W. Tang and J. Wang, Methanol sensing micro-gas sensors of $\mathrm{SnO}_{2}-\mathrm{ZnO}$ nanofibers on $\mathrm{Si} / \mathrm{SiO}_{2} / \mathrm{Ti} / \mathrm{Pt}$ substrate via stepwise-heating electrospinning, J. Mater. Sci., 2015, 50, 4209-4220.

40 L. Zhu, Y. Wang, D. Zhang, C. Li, D. Sun, S. Wen, Y. Chen and S. Ruan, Gas Sensors Based on Metal Sulfide $\mathrm{Zn}_{1-x} \mathrm{Cd}_{x} \mathrm{~S}$ Nanowires with Excellent Performance, ACS Appl. Mater. Interfaces, 2015, 7, 20793-20800.

41 M. Liu, S. Ren, R. Zhang, Z. Xue, C. Ma, M. Yin, X. Xu, S. Bao and C. Chen, Gas Sensing Properties of Epitaxial $\mathrm{LaBaCo}_{2} \mathrm{O}_{5}$. $5+\delta$ Thin Films, Sci. Rep., 2015, 5, 10784.

42 X. Deng, S. Sang, P. Li, G. Li, F. Gao, Y. Sun, W. Zhang and J. Hu, Preparation, characterization, and mechanistic understanding of Pd-decorated $\mathrm{ZnO}$ nanowires for ethanol sensing, J. Nanomater., 2013, 2013, 150.

43 X. Liu, N. Chen, X. Xing, Y. Li, X. Xiao, Y. Wang and I. Djerdj, A high-performance $n$-butanol gas sensor based on $\mathrm{ZnO}$ nanoparticles synthesized by a low-temperature solvothermal route, $R S C A d v .$, 2015, 5, 54372-54378.

44 B. Han, X. Liu, X. Xing, N. Chen, X. Xiao, S. Liu and Y. Wang, A high response butanol gas sensor based on $\mathrm{ZnO}$ hollow spheres, Sens. Actuators, B, 2016, 237, 423-430. 